\title{
Policy-making under uncertainty
}

\author{
RORY SUTHERLAND \\ Ogilvy London, London, UK \\ and \\ Ogilvy Change, London, UK
}

\begin{abstract}
The problem with decision-making in an institutional setting is that it is often more important for one's reputation and job security to appear to be logical than it is to be truly effective. Indeed, a far lower burden of proof is applied to ideas and suggestions that accord with simple economic axioms than to those that are oblique, counterintuitive or employ second-order thinking. Hence, the best new ideas generated by behavioural science will and should often lie outside the bureaucrat's natural comfort zone; any difficulties encountered by behavioural scientists should not surprise us: like the sting of an antiseptic, they are proof that the treatment is working.
\end{abstract}

Submitted 12 December 2017; revised 1 March 2018; accepted 13 March 2018

The article by Sanders et al. (2018) is an astute and, at times, chastening read. It raises many vital questions, many of which I suspect will never go away. Realistically, for instance, the issue of spillover effects will always be with us. So, too, will questions of replication and wearout, the complexity of social contagion and diffusion and doubts as to whether behaviours exhibited by Western, educated, industrialised, rich and developed (WEIRD) subjects are representative of the wider human population.

In fact, I suggest we all plan for a life in which we will be embroiled in these same arguments right up to the day we retire (and finally claim our behaviourally optimised, opt-out pensions). We should not be surprised by this. In fact, we should welcome it. After all, the very ambiguities and uncertainties that give rise to these arguments are a necessary condition - perhaps even a highly desirable outcome - of what we are all trying to do, which is, quite simply, to broaden the consideration set for policy ideas. 
To understand why these painful processes are a necessary consequence of this mission, all that is needed is a little exercise in reframing. The conventional behavioural economics view is that conventional economics leads to bad policy because it is sometimes wrong. This is true, as far as it goes, but that does not mean it is the job of behavioural economics to be consistently 'right'. Perhaps the most we can hope for - indeed, the most we should hope for - is for behavioural economics over time to devise new solutions that, rather than being unambiguously 'right', are merely 'less wrong'. This requires that we adopt a new approach to attacking the current economic hegemony, one that is honest enough to accept that complex behavioural problems will never submit to the same neat and unambiguous certainties found in engineering, say, or Newtonian physics.

In this new approach, instead of criticising conventional economics because it is wrong (after all, 'all models are wrong'), we should criticise economics for being creatively limiting. To me, the real cost of economics resides not in its wrongness, but in its narrowly reductionist approach to defining and solving problems of human behaviour - an approach that is, quite simply, imaginatively stultifying.

Robert Zion, the famous social psychologist, once remarked that cognitive psychology is "social psychology with all the interesting variables set to zero." If that is so, it is still much more nuanced than economics, which is effectively social psychology with all but one of the variables set to zero.

Let me explain in a little more detail what gives rise to these creative limitations.

Quite simply, the many assumptions and simplifications that are necessary for economics to maintain its 'mathiness' come at a cost: they impose huge limitations on its ability to solve problems. Every time you remove a variable from a model for the purposes of neatness or mathematical tractability, you are essentially disabling a lever of intervention by which the problem your model addresses may be solved.

If you assume that the only thing that matters in a wine is (1) alcohol content and (2) price (i.e., you ignore climate, terroir, viticulture, varietal, branding, bottle and label design), there are only two remaining ideas you can have for improving your wine: make it cheaper and/or add some alcoholic strength. If you assume that human decision-making consists of a series of perfectly objective, individualistic, standalone, non-path-dependent, context-free, status-free, utility-maximising choices made in an ergodic environment of perfect trust and perfect information, then every one of these assumptions closes off a potential avenue for understanding behaviour, let alone changing it.

As Sir Christopher Llewellyn Smith observed about UK energy policy: "When I ask an economist for suggestions, it always boils down to bribing 
people." ${ }^{1}$ Or, to borrow a phrase from the advertising industry, "To a man with only a hammer, everything looks like a nail."

In fact, the only modes of changing behaviour that remain for you to use are those in the field of rational incentives - meaning that the sole remaining lever of intervention, rather conveniently, lies squarely in the domain of the economists themselves. It is as if medical diagnosticians were only to diagnose illnesses that they themselves were uniquely qualified to cure.

Economists have somehow contrived a means of defining problems that leaves them with a perfect monopoly on solving them. There is no room in this model for marketing or advertising, for instance; indeed, taken at its purest and most unambiguous worst, economics leaves no role for reframing a problem or anchoring a price, for providing guarantees or reassurances, for overcoming inertia, for signalling, for satisficing, for shame, for norms, for psychophysics, for choice architecture, for social proof or any of a host of perceptual and persuasive tools that can have a decisive effect on how people think, decide and act.

Moreover, even if you could somehow create a world that more closely approximated to the economist's narrow conception, there remains an insurmountable problem - which is that our brains have not evolved to make decisions in such a world. Our perception is not remotely objective, for instance. This is because in honing our senses, evolution favours fitness over accuracy. We detect contrasts rather than absolutes. We are also a social species, who have evolved to make context-dependent, path-dependent, status-seeking, satisficing choices made using a heuristic toolbox in a non-ergodic environment of uncertain trust and highly imperfect information. After all that, two fairly similar people may even perceive the same reality in two different ways. The simple monosyllable 'new' might convey to someone high in 'openness' an exciting new possibility, whereas his or her more conservative neighbour might perceive the word as a threat.

To change the behaviour of a creature who has evolved in such a way requires much more than the linear exercise of conventional reason. It requires reverse reasoning, creative hypotheses and experimentation to hack the unconscious mind - and to uncover the often unspoken and unconscious 'whys' and 'why-nots' that ultimately drive our behaviour. Some of these hypotheses may even be highly counterintuitive, and may seem to economists to be pandering to what they would call 'human irrationality'. I will give two hypothetical examples.

1 Spoken at the Santa Fe Institute, 6 August 2012 in a talk entitled 'Complexity: A Discussion of Life, Scale, and Civilisation'. 
Imagine you have two products for sale. Product A appears to offer more features than product $\mathrm{B}$ and is also offered at a lower price. To an economist, this is the easiest decision imaginable. Higher utility plus lower cost. Everyone should buy A. In reality, however, many consumers would be baffled by this choice. Since they are making a decision without perfect knowledge of the two products (they do not know how reliable they both are, for instance), they might assume that there must be some dark reason why the purveyor of the ostensibly superior product $\mathrm{A}$ is not confident enough to demand a price premium for it. The most likely behaviour, I suspect, is for the bemused consumer to buy neither. The maker of product A, regardless of the pricedemand curve, would be better off asking for a slightly higher price than that asked for product $\mathrm{B}$, whatever economic logic might dictate. This is not irrationality - it is human second-order social intelligence applied to an uncertain and ultimately unknowable world.

A second example: I recently proposed testing the lowering of the ceiling on which pension contributions receive tax relief. This was based on the theory that, under such conditions, pension contributions overall would increase. The success in the UK of ISAs should, ${ }^{2}$ I think, be partially attributed not only to the tax advantages they confer, but also to the finite amounts that you are allowed to save annually, which set a target for savings and create a feeling of loss in any year in which you fail to make an adequate investment in the scheme. With a very high ceiling, no such feeling of loss is triggered.

Both of these ideas conflict with economic theory. In fact, anyone adopting such an approach would have to prove their case through experimentation before they would be allowed to proceed.

Interestingly, someone proposing the opposite idea - in other words, the idea that is congruent with economic theory - is unlikely to be held to anything like the same burden of proof. This is, when you think about it, an extraordinary example of a bias. It seems the extent to which you are required to justify a course of action is proportionate to the extent to which your recommendation contradicts mainstream economic assumptions.

Have you ever heard of someone being asked to perform a randomised control trial to prove that when you reduce a price then demand increases? Yet this economic assumption is not universally true. I once proposed to a

2 For the benefit of overseas readers, an ISA is a special savings vehicle in the UK whereby savers may put a finite amount of money annually into a fund (cash, equities or both) where it is exempt from capital gains tax - the amount has recently increased from $£ 15,240$ to $£ 20,000$ - a decision that may be a mistake. If the amount were $£ 5000$, someone who can save $£ 4000$ a year may save the whole amount. With a $£ 20,000$ allowance, they can always mentally convince themselves that they can save $£ 8000$ 'next year'. 
client that they would sell more of a product if they raised the price, and they tested it thoroughly (luckily I was right). Yet no one would demand a test before dropping the price of an underperforming product - because anything congruent with economic theory can be passed on the nod.

So why, given its immense limitations, does economics hold this remarkable dominance in government and business decision-making? Here, again, a mixture of behavioural science and evolutionary psychology can provide a possible answer. What we need to realise is that it is the very oversimplification that makes economic theory so creatively infertile that also makes it so appealing to anyone making decisions in an institutional setting.

It can be explained very simply by what Gerd Gigerenzer calls 'defensive decision-making'. And it is further illuminated by the work of Dan Sperber and Hugo Mercier on the real reasons we evolved a faculty of reason - not to make decisions, but to defend and justify them. We are not a rational animal; we are a post-rationalising animal: "The study of reasoning has been dominated by a normative goal and a descriptive expectation: the goal of discovering and making explicit a general method that could produce good reasoning and the expectation that actual human reasoning would be guided by an approximation of such a method. Both the goal and the expectation have, so far, been disappointed. This failure is not an accident. There is a principled explanation for it. The procedures of intuitive inference, we have argued, are unconscious, opportunistic, and diverse. The idea that intuition might consist in following a general method makes little sense" (Mercier \& Sperber, 2017, p. 173).

Interestingly, very few people in their private consumption make much use of economic logic. Accountants do not perform a cost-benefit analysis when buying a car. In making consumer decisions, our principal concern is that we believe we will be happy with the consequences in the light of our conscious and unconscious intentions, and that there is a low chance of a disastrous outcome. In making business decisions, or government decisions, unless we are entrepreneurs or mavericks, we have a different unconscious aim: more important than making a decision with beneficial consequences is making a decision that is easy to explain and defend, especially should the consequences turn out badly.

In reality, the quality of reasoning does not necessarily correspond to the quality of a decision. But in institutional decision-making, where you have to defend your decisions to others, the quality of your reasoning is more important than the quality of your decisions. A well-reasoned decision is easy to defend, no matter how bad the outcome.

Economic logic has hence become the new IBM: nobody ever gets fired for using it. And its lack of creativity is what appeals to the civil servant, the 
bureaucrat or the risk-averse manager. Although decisions taken using economic logic may turn out to be inefficient or suboptimal, there is very little downside risk to adopting them. If you maintain the pretence that everyone is economically rational, you can fail and still keep your job. If you do anything economically counterintuitive, however imaginative, your job is at immediate risk if anything turns out badly. As Keynes once remarked, "Worldly wisdom teaches that it is often better for the reputation to fail conventionally than to succeed unconventionally." Hence, it is the economics discipline's very lack of creativity that contains the secret to its appeal, because by misrepresenting reality it provides an uncontentious rationale to justify any action taken in accordance with its axioms.

Behavioural economics does not have this quality, and if behavioural scientists wish to be a source of imaginative solutions, they should not seek to acquire it. It is a spectacular achievement of behavioural science, for which the Behavioural Insights Team deserves much credit, that in cabinets, mayoral offices, town halls, think tanks and boardrooms all over the world it is now possible to hold conversations premised on the idea that there may be more to behaviour than the narrow pursuit of economic self-interest, but do not expect these ideas to be adopted easily. Imaginative ideas always require more justification than standard rational approaches. I speak as someone who has spent thirty years in advertising. Every truly interesting idea contains something that does not quite make conventional sense. Red Bull tastes horrid. Stella Artois advertises itself as expensive. Marmite is proud of the fact that many people hate it. These ideas are always painful to sell. But if it does not hurt, maybe you are not doing it right.

\section{References}

Mercier, H. and D. Sperber (2017), The Enigma of Reason, London, UK: Allen Lane.

Sanders, M., V. Snijders and M. Hallsworth (2018), 'Behavioural science and policy: where are we now and where are we going?', Behavioural Public Policy, 2(2): 144-167. 